\title{
Effective Training Program for Gap Closing In Construction Industry
}

\author{
Mrs. Shruti Wadalkar ${ }^{1}$, Dr. S.S. Pimplikar $\mathrm{r}^{2}$ \\ ${ }^{1}$ (Department of Civil Engineering, Pad. Dr D.Y.P.I.E.T./ pune, india) \\ ${ }^{2}$ (Department of Civil Engineering, Maharashtra Institute of Technology / pune, india)
}

\begin{abstract}
In developing Country like India there are various small construction companies. In this paper author suggest an equation for competency required by project manager in the Indian construction company. The training programme which is planned for eight days consists of total fourteen modules. The competencies are broadly classified here into four broad categories viz, Functional, Behavioral, Communication and IT. for the competency assessment exercise that was done for its 39 managers. The managers are like project manager, planning manager, construction manager etc.
\end{abstract}

Keywords - Competency, competency mapping, gap closing, competency assessment, training programme.

\section{INTRODUCTION}

Human Resource is the valuable asset of any construction company. As construction projects are highly complex in nature, there are number of activities associated with the progress of any construction project and the control and effective completion of activities depend upon the HR management of the organization. The level of competition in the construction industry has risen due to the opening of market in the international industry and the use of new technology by the competitors. As success of construction industry is through the project success, to achieve it, a project management team is required to attain high performance to stand in the global market. In order to maintain the supremacy over the other competitive firms, it is required to increase the unique value of the organization and for that reason competency mapping is required to be done at various levels in the organization. By finding out competency gaps proper measures for gap closures can then be suggested.

In the present paper analysis is done on data collected from a reputed construction company about the competencies of its managers which gives idea about the areas and the skills where there are predominant competency gaps. A training programme for the same is designed and is presented here in detail.

\section{WHAT IS COMPETENCY ?}

Any characteristics required for performing a given task, activity, or role successfully can be considered as competency. Competency may take any form like knowledge, attitude, skill, motives, values or self concept.

Organizations in the construction and engineering industry often undertake large scale projects. To successfully perform these projects, it is imperative for these organizations to have a clear understanding of their general areas of expertise. Some professionals and researchers refer to these general areas of organizational expertise as core competencies Although there is great variability in what different organizations include in their competency profiles, the Construction Industry Institute defines a competency as a project work process that requires a group of critical capabilities distinctly falling in one of four categories- knowledge, skills, abilities, and experience To optimize profitability and productivity, engineering organizations must identify their core organizational competencies (CTCs) and make periodic assessment of capabilities that define these competencies within the organization. In addition, the organization must have a keen understanding of the requirements necessary to develop and maintain these core competencies and should determine the availability of personnel required to maintain these competencies.

\section{WHAT IS COMPETENCY MAPPING?}

Competency mapping is the process of identification of the competencies required to perform successfully a given job or role or set of task at a given point of time. It consists of breaking a given role or job into its constituent tasks or activities and identifying the competencies (technical, managerial, behavioral, conceptual knowledge and attributes skills, etc.) need to perform the same successfully. On the other hand competency assessment is the evaluation of the extent to which a given individual or a set of individuals posses these competencies required by a given role or set of roles or level of roles. Assessment centers use multiple methods and multiple assessors to assess the competencies of a given individual or a group of individuals. In order to enhance objectivity they use trained assessors and multiple methods including psychometric tests, simulation exercise, presentation, in-basket exercises, interviews, role play, group discussion etc. The methods 
to be used depend upon the nature of competencies. Competencies can be achieved by experts in consultation with line manager, current and past role holders, supervisors, internal customer, subordinates and other role set members who interact with the person.

\section{TRAINING}

Millovich \& Boudreau (1994) Give Definition Of Training As "Training Is A Systematized Procedure Of Modifying The Behavior, Intelligence And Provoking OF Present EMPloyees To

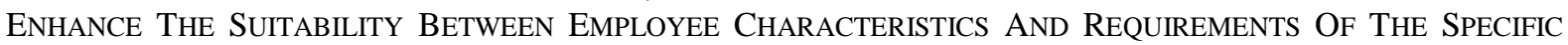
JOBS.”

G.L. NARAyanapPa (2009), Training Normally Refers IMPaRting Teaching To LOWER LeVEL Employees On How To Perform Their Present EMployment Positions. The First Phase Of Training Should Include A NeEds Assessment. An Enquiry Should Be Carried Out To Identify The Jobs, Personnel AND Various Departments For Which Training Is Essential. Job ANAlysis AND Performance Measurements are Essential For This Purpose. The Second Phase Involves The Designing Of Training Programmes. Based On The Requirements And Assessments, The Training Objectives ANd Contents CAN Be Formulated. In The Third Phase The DeCision About The Various Training Methods to Be adopted In Their Particular Organizations Needs To Be Done. The Prime Decision For Choosing A Training Method Is, Whether To IMPART On-THE-Job Training Or OfF-THEJob Training. Final Phase Of Training Should Evaluate The Effectiveness Of The Programme In Terms Of Employee Reactions, Learning Behavior Transferred To The People And Bottom Line RESULTS.

\section{RELATED WORK}

Amin Akhavan Tabassi, A.H. Abu Bakar (2008) were exposed some barriers in the training and motivation of the construction workers and provides solutions for the government and companies in Iran. Also, it reveals the effects of unskilled labour on the quality of construction projects in Mashhad.

National skill development council has done their Study on mapping of human resource skill gaps in India till 2022, NSDC report (2010). In this report they had given overall scenario of construction industry in India, various skill required, skill gaps present in the various human resources. This report serves guideline for designing of training and development programme for HR development in construction industry.

ddie W. L. Cheng and Heng Li (2006) has done their research on improving and sustaining job performance. It involves well planned employee evaluation criteria to assess employee performance. It is suggested that construction companies should pay more attention to the importance of job performance evaluation, which can be done in a more thoughtful manner.

Juri L. De Coi, Eelco Herder, Arne Koesling, Christoph Lofi, Daniel Olmedilla, Odysseas Papapetrou, and Wolf Siberski (2007) in their research focused on the limitations and extends existing approaches for modeling competences in order to allow (semi)- automatic competence matching.

\section{DATA COLLECTION AND ANALYSIS}

One of the leading \& reputed construction companies had taken competency review for its 39 managers. Based on this review, major competency gaps in most of the managers were identified out. The competencies are broadly classified here into four broad categories viz, Functional, Behavioral, Communication and IT. From the competency assessment exercise that was done earlier the specific areas where development was needed on a priority basis, were identified. In this exercise the company had include the Project Managers, the Construction managers, some deputy mangers who possess the potential to shoulder more responsibility and also some senior planning engineers for a major region of their business territory. The data obtained from the competency mapping is presented in Table1. 


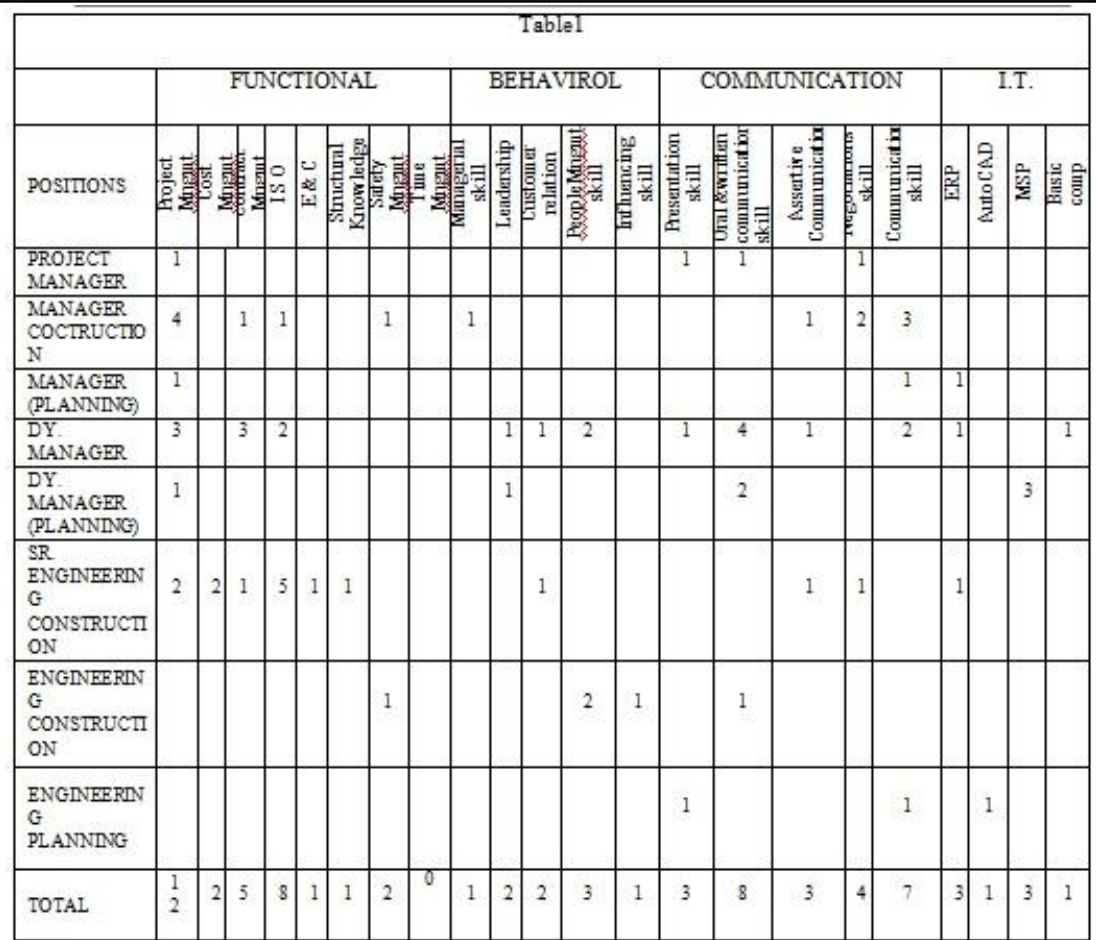

The following gaps were predominantly needed to be bridged i,e. from the analysis, the following areas for training or needs of development were identified.

1. Amongst Functional Competencies Project Management, Construction Management and ISO

2. For Communication, Oral and written communication skills.

3. For IT, ERP was identified, as the major developmental need.

With the consent of the company authorities, a training programme suggested is as follow

VII.

1. Training programme Day 1

DETAILED TRAINIG PROGRAMME

Total Duration: 6 hrs

Module 1

Orientation

Apply and implemented TQM as a managerial Philosophy

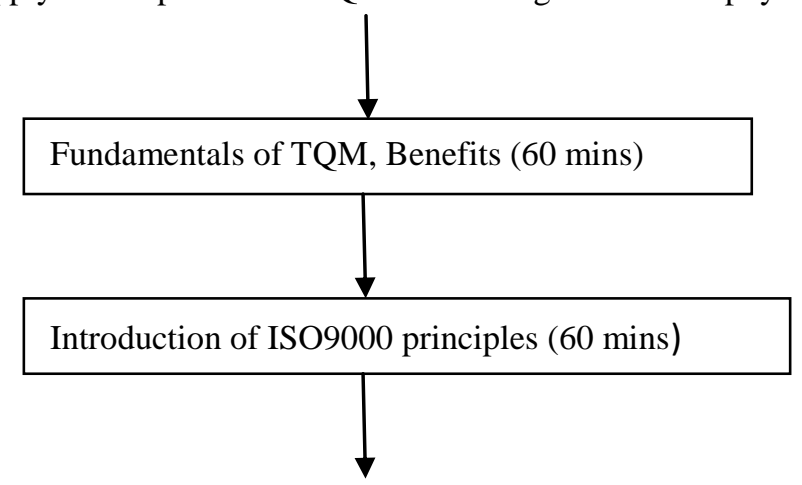

Group activity 

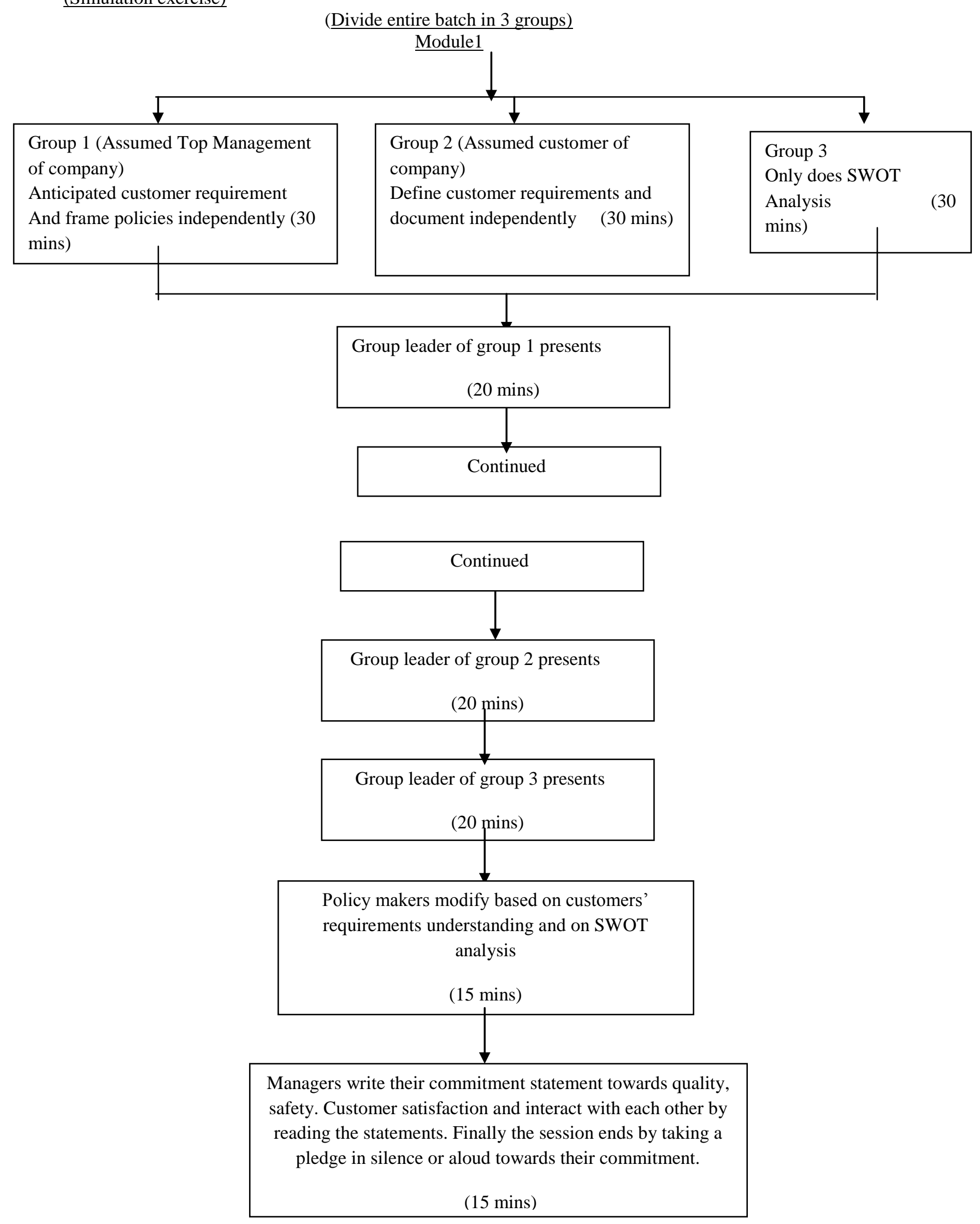
2. Training programme Day 2

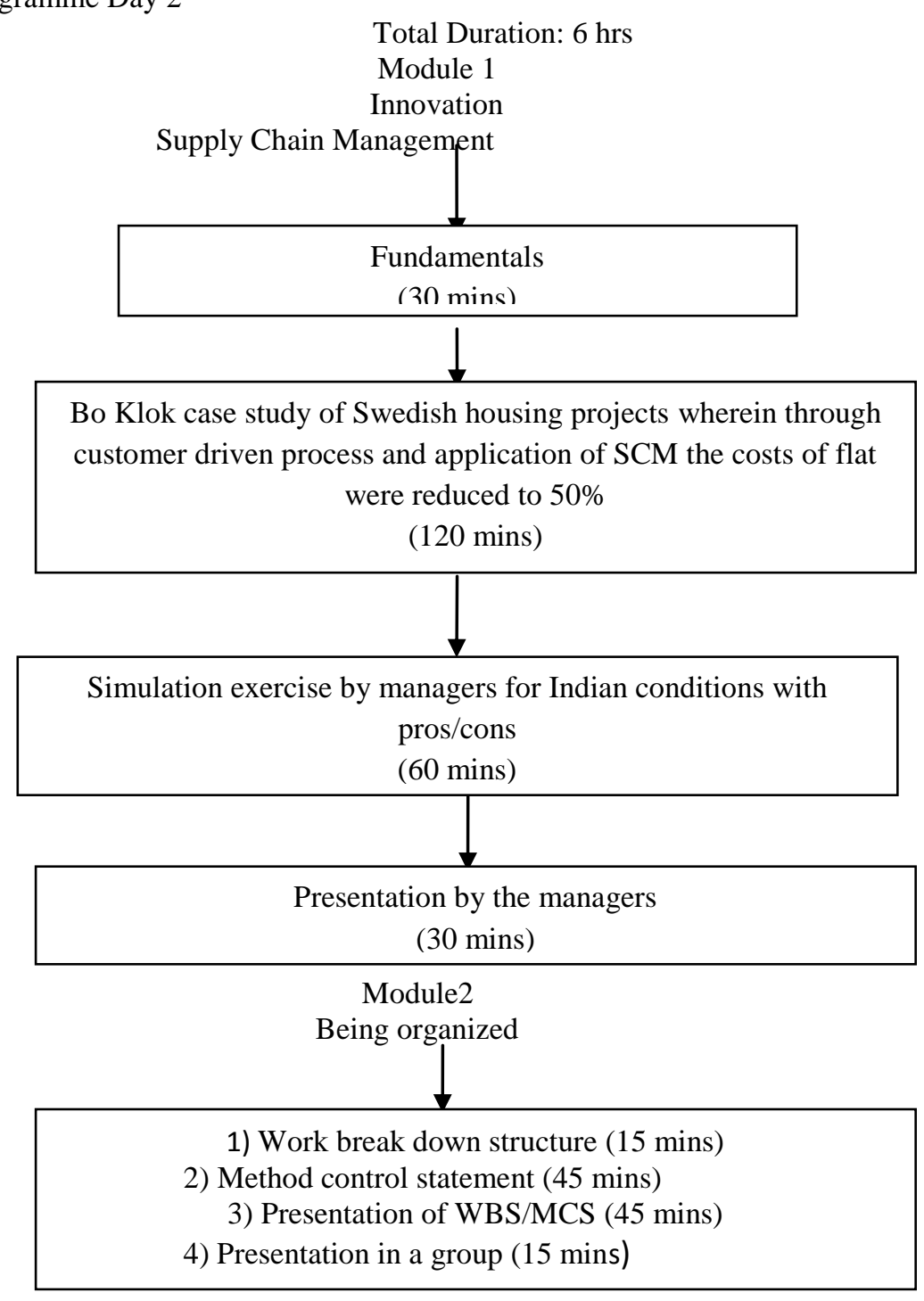

3. Training Programme Day 3

Total Duration: 6 hrs

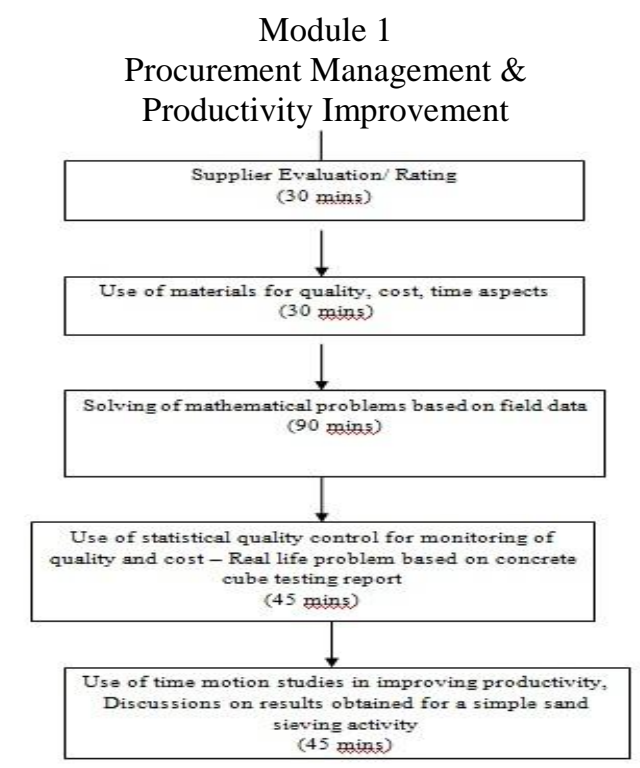

www.iosrjournals.org 
Module 2

Cost Control

1) Cost of Rework, cost of quality and direct indirect

costs (60 mins)

2) Analyzing performance variances (30 mins)

3) Sensitivity analysis (30 mins)

4. Training Programme Day4

Total Duration: 6 hrs

Module 1

Construction Equipment Management

1) Judicious selection of construction equipment (30 mins)

2) Exercises on sizing- Matching using mathematical models (60 mins)

3) Exercises on economic analysis based on various costs including downtime costs and productivity. (60 mins)

4) Concept of construction equipment bank (30 mins)

5) Simulation exercise between 2 groups- 1 representing the clients and other renresenting the eauinment manufacturer $(60 \mathrm{mins})$.

Module 2

Construction Safety Management

Technical issues, organizational issues, performance monitoring and measurement through a comprehensive questionnaire survey

(120 mins.)

5. Training Programme Day

Total Duration: 6 hrs

Module 1

Contract Administration

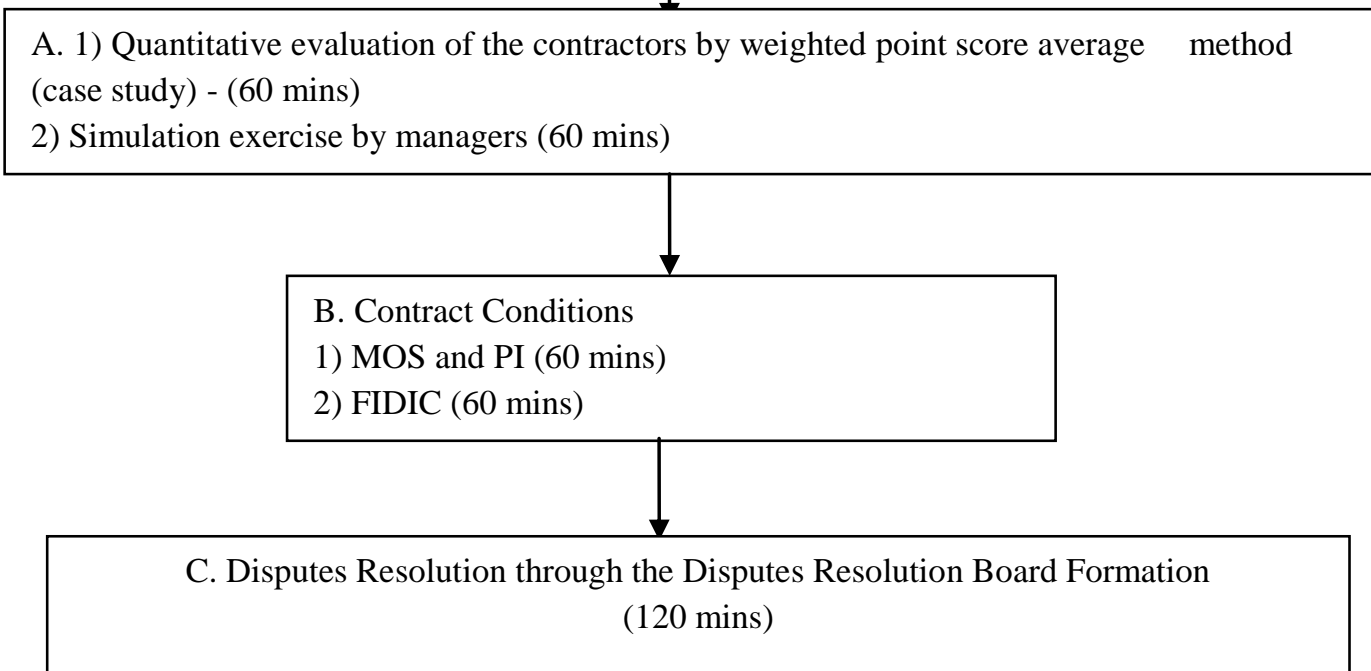

www.iosrjournals.org 
6. Training Programme Day 6

Total Duration: 6 hrs

Module 1

Continuation of Contract Administration

Make up the DRB exercise for the commonly occurring disputes related to SP (120 mins)

1. RAMP methodology of risk assessment and mitigation. (90 mins)

2. Simulation exercise by managers by identifying the various risks they anticipated and how to Mitigate them through RAMP. (45 mins)

3. Introduction to the various risk mitigation policies developed by CIDC (45 mins)

4. Exercise on mathematical models used for risks assessment and mitigation. (60 mins)

7. Training Programme Day7

Total Duration: 6 hrs

Module 1

Software Training

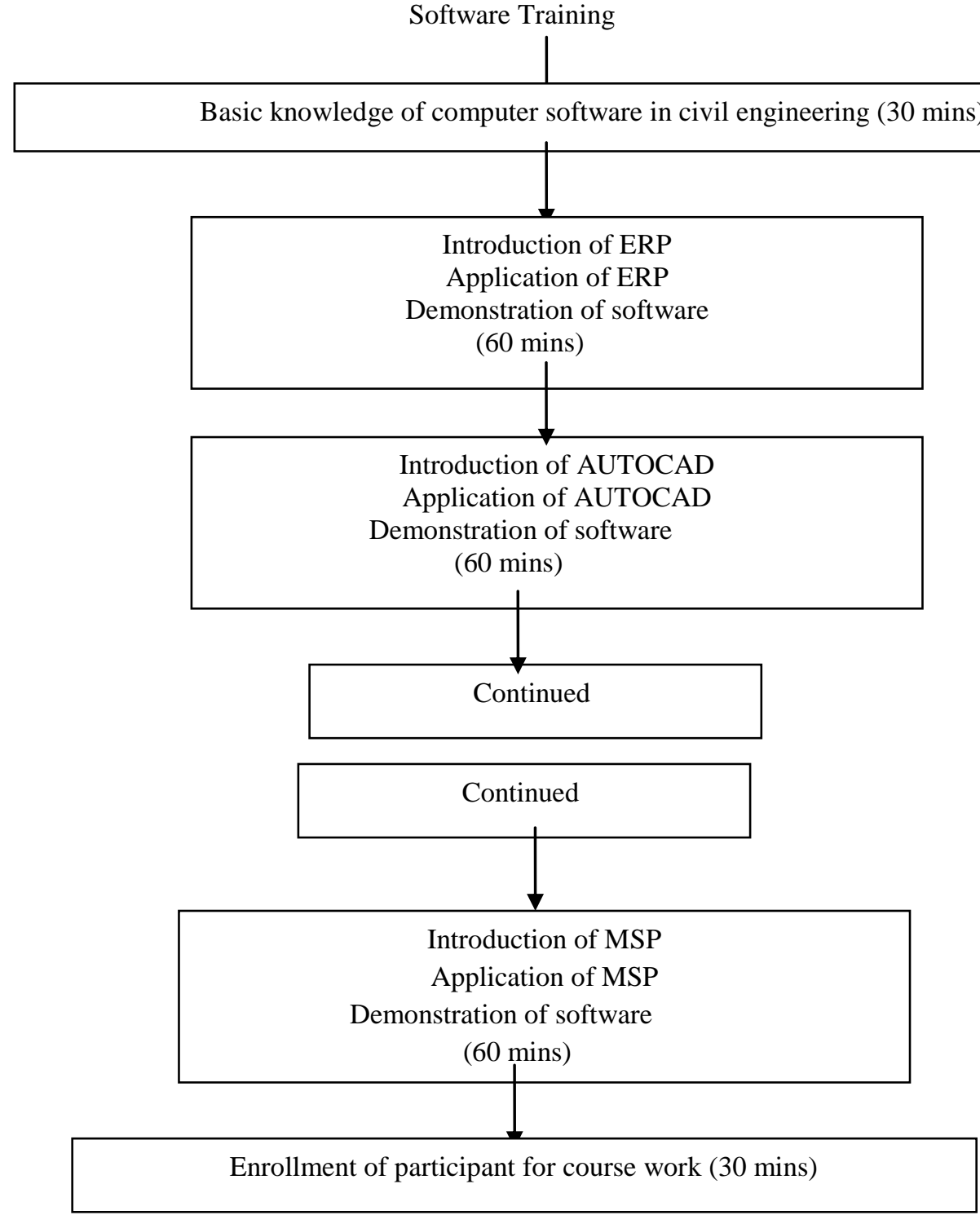


Module 2

Structural model

Structural concepts by using case studies

(120 mins)

8. Training Programme Day8

Total Duration: 6 hrs

Module 1

Innovtive construction material

\begin{tabular}{|c|}
\hline $\begin{array}{l}\text { 1. Fly ash } \\
\text { 2. Silica Fumes } \\
\text { 3. Self Compacting Concrete } \\
\text { 4. Other alternative materials } \quad(120 \text { mins })\end{array}$ \\
\hline $\begin{array}{l}\text { Module } 2 \\
\text { ( Trench less Technology) }\end{array}$ \\
\hline $\begin{array}{l}\text { 1. Advantages } \\
\text { 2. Surveys } \\
\text { 3. Applications in India and abroad taking the aid of video film there on } \\
\text { 4. Introduction to a few trenchless methods ( } 240 \text { mins })\end{array}$ \\
\hline
\end{tabular}

\section{CONCLUSION}

The training programme developed for the construction managers was a tailor made, using the identified competency gaps. The authors suggest such training programme especially, so that the objective of exercises like competency assessment, identification of areas of improvement etc. can be served more efficiently.

First day modules can serve as a gap closure for competency gaps related with quality, ISO concept and communication gaps like oral and written communication.

Second day's modules give basic of Project management and Time management.

Third and fourth day's modules provide basic ideas about material management, time and cost management. Topics of Third and Fourth day can be helpful for closing the gaps found in construction management. Identified competency gaps in Planning managers, and construction engineers like time and cost management, equipment and material management etc. can be closed by Third and Fourth day's modules.

Fifth and Sixth day's modules are useful for closing the gaps related to contract management IT's and structural knowledge gaps can be closed with the help of Seventh day's modules. Eighth day's modules provide knowledge of innovative materials and technology to the concerning engineers.

Thus the training programme serves as an effective measure for closing the competency gaps in the construction company, which have been identified through the competency mapping process.

\section{Journal Papers:}

\section{REFERENCES}

[1]. Amin Akhavan Tabassi, A.H. Abu Bakar (2008) "Training, motivation, and performance: The case of human resource management in construction projects in Mashhad, Iran” International Journal of Project Management 27 (2009) 471-480

[2]. Eddie W. L. Cheng and Heng Li (2006) "Job Performance Evaluation for Construction Companies: An Analytic Network Process Approach" Journal Of construction engineering and management (C) ASCE / AUGUST 2006.

[3]. G.L. Narayanappa (2009) "Human Resource Management (Text and Case Studies)" $1^{\text {st }}$ ed. Scitech publications (India) pvt. Ltd.

[4]. Juri L. De Coi, Eelco Herder, Arne Koesling, Christoph Lofi, Daniel Olmedilla, Odysseas Papapetrou, and Wolf Siberski (2007) “ A model for competence gap analysis" http://dspace.ou.nl/bitstream/1820/1119/1/model_for_competence_gap_analysis.pd"

[5]. National Skill Development Corporation, India NSDC (2010) "Study on mapping of human resource skill gaps in India till 2022" http://www.nsdcindia.org

[6]. V.P. Michael (1998) "Human Resources Management and Human Relations" $5^{\text {th }}$ ed. Himalaya publishinghouse, Mumbai. $n$ italic WWW.iosrjournals.org 